\title{
Cuckoo search algorithm based for tunning both PI and FOPID controllers for the DFIG-Wind energy conversion system
}

\author{
Mostafa A. Al-Gabalawy ${ }^{1}$, N. S. Hosny ${ }^{2}$, Shimaa A. Hussien ${ }^{3}$ \\ ${ }^{1,2}$ Electrical power and Control Department Pyramids Higher Institute for Engineering and Technology, Egypt \\ ${ }^{3}$ Electrical Department Faculty of Engineering, Princess Nourah bint Abdulrahman University, Saudi Arabia
}

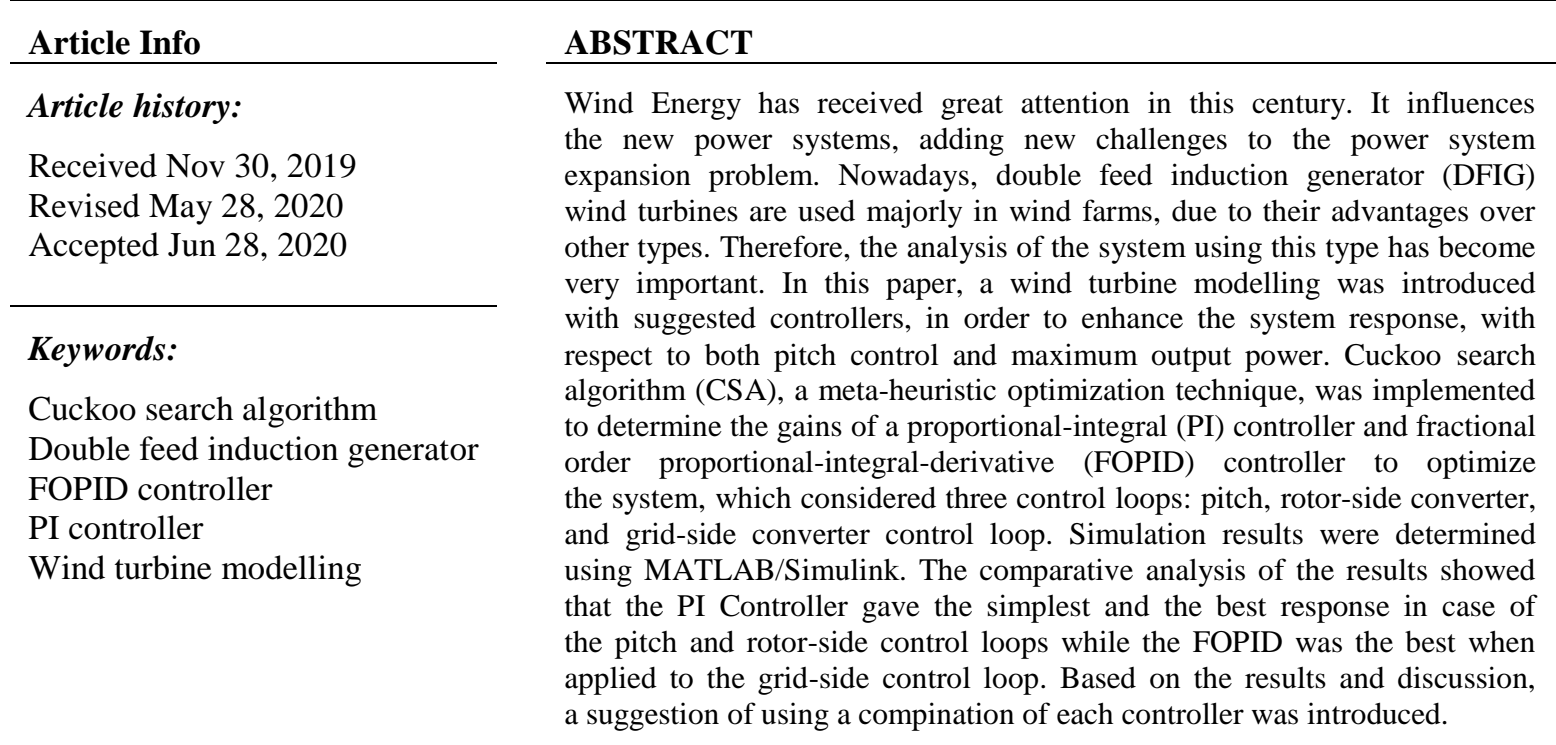

Copyright $@ 2020$ Institute of Advanced Engineering and Science. All rights reserved.

\section{Corresponding Author:}

N. S. Hosny,

Electrical power and Control Department,

Pyramids Higher Institute for Engineering and Technology,

Giza, Egypt.

Email: nesreen.samir@gmail.com

\section{INTRODUCTION}

Recently, wind power has become an important alternative for electrical power generation. It is expected in the following decades to expand the power supply systems using this type. Consequently, literature review has been conducted on the wind turbine control objectives and approaches to understand the past, present, and possible future techniques [1]. Control techniques were applied to both turbine pitch and generator. In this section, some of the most recent techniques of DFIG wind turbines will be reviewed, to help to develop more advanced controllers for this system in order to enhance the response by increasing the speed and maximize the output power.

A control model for the DFIG wind turbine was introduced in [2]. Particle swarm optimization (PSO) technique was used to find the optimum controllers parameters, which enhanced the system stability in case of a small or a large disturbance. Another modelling to this wind turbine type was presented [3]. The DFIG, the converter, and the electrical grid were described. Different control techniques were discussed for both normal operation or under voltage dip conditions. They included the speed control, torque control, and reactive power control from the rotor-side converter. Also, grid-side converter reactive power and DC 
voltage control were evaluated. A comparison between real wind turbine data and the simulation results were presented.

A variable speed wind turbine control is proposed to determine the turbine optimum reference speed, which would lead to maximum output power and increase the system efficiency [4]. The stability of the proposed controller was analyzed under wind speed variations, and the results showed that the controller is robust with these variations in the speed as in real systems. Paper [5] proposed a control model for the same purpose using the method of vector control, directly and indirectly. In [6], higher output power and better maximum power point tracking (MPPT) could be achieved using a new technique. The technique was compared with conventional methods and verified mathematically.

The reactive power control of wind farms were discussed in [7], taking into consideration the calculations of the reactive power limit. A numerical test system for the proposed method was established and showed the effectiveness of that method. A non-linear algorithm was proposed to control the system and increase the efficiency [8]. The connection between the machine and the grid was through a multi-level converter. The test of the proposed controller was carried out using MATLAB/Simulink, and the results analysis showed the validation of the proposed method.

The backstepping approach involving wind speed estimation was used to develop a non-linear control law for a variable speed wind turbine, which was equipped with DFIG [9]. The control objective involved tracking for the maximum wind power, rotor flux regulation with controlling the stator reactive power, and keeping DC link voltage constant. The wind estimator and the control law were verified using MATLAB/Simulink as well. Also, a backstepping robust controller for a 2.4 MW DFIG wind turbine was obtained in case of technical disturbances in the generator, along with the application of PSO to determine the optimum parameters [10].

Another method was introduced to control the same turbine type, performing control vector-oriented stator flux [11]. The proposed controller was a proportional- integral (PI) controller with correction. The results determined using MATLAB/Simulink of testing the controller showed that the system was feasible. The author in [12] proposed a design for a controller using the technique of static output feedback. The results were compared to an existing method to help to improve the system performance.

Control strategies were applied to the converter at the rotor side [13]. They involved Flux oriented control, voltage oriented control, direct torque control, and direct power control in order to achieve MPPT to get maximum efficiency. For that study, PSCAD/EMTDC software was used to implement the simulation results. Advanced differential evolution was applied to the optimal control problem in a multi- machine power system [14]. As faults on transmission lines affect the system stability, optimizing the objective was implemented using a PI controller. The parameters were tuned using the above mentioned algorithm. The results showed an enhancement to the overall system stability and performance. Based on gravitation laws, a new optimization method was used to tune the parameters of three PI controllers, which were used to design a more stable system, if subjected to large disturbances, in comparison with common genetic algorithm (GA) and PSO optimization methods [15].

In this paper, a control model using the recent MATLAB/Simulink has been developed. Both PI and FOPID controllers were used and their gains were optimized using CSA for three control loops: pitch, rotor-side converter, and grid-side converter. The system behavior has been observed under steady-state condition and the results were analyzed and compared to determine the best one, which would achieve the best pitch control and maximum power. The error function of each controller was optimized using the integral of absolute error (IAE), integral of squared error (ISE), iIntegral of time multiplied by absolute error (ITAE), and integral of time multiplied by squared error (ITSE). The values of the errors were less for the first and second control loops when the PI controller was implemented while they were less for the third loop with using the FOPID controller. The comparison between the error's values led to the conclusion of that using a compination of both PI and FOPID controllers instead of using only one of them might be considered. Detailed description of the proposed system mathematical model, control loops, optimization technique would be introduced in this paper along with the results and their analysis. This model could be used in real power applications.

The structure of this paper is as follows: Section 2 introduces the mathematical modelling for the problem. Section 3 describes the proposed controllers. The used optimization technique is introduced in section 4 . The simulation results, their analysis, and the comparison between them are in section 5. Finally, in section 6 , a summary for the conclusions is presented.

\section{MATHEMATICAL MODELLING}

In this section, the mathematical modeling of the DFIG and the wind turbine would be presented. 


\subsection{DFIG mathematical model}

There are some assumptions for modelling induction machines in the $d q$ domain. These assumptions are that the air gap is uniform, all Eddy currents, friction, and windage losses are neglected, and both the stator and rotor windings are identical. Also, the studied induction machine works under the condition in which the magnetic fields are unsaturated and it is magnetic linear [16].

The relationship between $d q$ currents and $a b c$ currents can be expressed as:

$$
i_{s, d q}=T_{s, a b c \rightarrow d q} \times i_{s, a b c} \text {, or, } i_{s, a b c}=T_{s, d q \rightarrow a b c} \times i_{s, d q}
$$

where,

$$
i_{s, a b c}=\left|\begin{array}{l}
i_{a}(t) \\
i_{b}(t) \\
i_{c}(t)
\end{array}\right|, \text { and } i_{s, d q}=\left|\begin{array}{l}
i_{s d}(t) \\
i_{s q}(t)
\end{array}\right|
$$

$T_{s, a b c \rightarrow d q}$, and $T_{s, d q \rightarrow a b c}$ are the transformation matrices for stator windings [16].

Similarly, for stator voltages:

$$
v_{s, d q}=T_{s, a b c \rightarrow d q} \times v_{s, a b c} \text { or, } v_{s, a b c}=T_{s, d q \rightarrow a b c} \times v_{s, d q}
$$

where,

$$
v_{s, d q}=\left[\begin{array}{l}
v_{s d}(t) \\
v_{s q}(t)
\end{array}\right], \text { and } v_{s, a b c}=\left[\begin{array}{l}
v_{a}(t) \\
v_{b}(t) \\
v_{c}(t)
\end{array}\right]
$$

For rotor windings,

$$
\begin{aligned}
& i_{r, d q}=T_{r, a b c \rightarrow d q} \times i_{r, a b c} \\
& v_{r, d q}=T_{r, a b c \rightarrow d q} \times v_{r, a b c}
\end{aligned}
$$

and,

$$
\begin{gathered}
i_{r, a b c}=T_{r, d q \rightarrow a b c} \times i_{r, d q} \\
v_{r, a b c}=T_{r, d q \rightarrow a b c} \times v_{r, d q}
\end{gathered}
$$

where,

$$
i_{r, d q}=\left[\begin{array}{l}
i_{r d}(t) \\
i_{r q}(t)
\end{array}\right], v_{r, d q}=\left[\begin{array}{l}
v_{r d}(t) \\
v_{r q}(t)
\end{array}\right], i_{r, a b c}\left[\begin{array}{l}
i_{A}(t) \\
i_{B}(t) \\
i_{C}(t)
\end{array}\right], \text { and } v_{r, a b c}\left[\begin{array}{l}
v_{A}(t) \\
v_{B}(t) \\
v_{C}(t)
\end{array}\right]
$$

For the flux linkage as in (9) and (10), it is given that $d q$ windings are orthogonal. There is no mutual inductance between $\mathrm{d}$ and $\mathrm{q}$ windings. Therefore, for stator windings, due to that the leakage flux caused by rotor currents does not cross the air gap.

$$
\begin{aligned}
& \lambda_{s d}=\left(L_{l s}+L_{m}\right) i_{s d}+L_{m} i_{r d} \\
& \lambda_{s q}=\left(L_{l s}+L_{m}\right) i_{s q}+L_{m} i_{r q}
\end{aligned}
$$

Combining the above four equations, flux linkage equation could be obtained as follows:

$$
\left[\begin{array}{l}
\boldsymbol{\lambda}_{s, d q} \\
\boldsymbol{\lambda}_{r, d q}
\end{array}\right]=\left[\begin{array}{cccc}
L_{s} & 0 & L_{m} & 0 \\
0 & L_{s} & 0 & L_{m} \\
L_{m} & 0 & L_{r} & 0 \\
0 & L_{m} & 0 & L_{r}
\end{array}\right]\left[\begin{array}{l}
\boldsymbol{i}_{s, d q} \\
\boldsymbol{i}_{r, d q}
\end{array}\right]
$$


where,

$$
\begin{aligned}
& L_{s} \triangleq L_{l s}+L_{m}, \text { and } L_{r} \triangleq L_{l r}+L_{m} \\
& \lambda_{s, d q}=\left[\begin{array}{l}
\lambda_{s d}(t) \\
\lambda_{s q}(t)
\end{array}\right], \lambda_{r, d q}=\left[\begin{array}{l}
\lambda_{r d}(t) \\
\lambda_{r q}(t)
\end{array}\right],
\end{aligned}
$$

The bold letters mean that these variables are in vector form.

The stator real and reactive power can be obtained as:

$$
P_{s}+j Q_{s}=\left(v_{s d}+j v_{s q}\right)\left(i_{s d}+j i_{s q}\right)^{*}
$$

* denotes the conjugate of the given complex-valued vector,

Similarly, for the rotor real and reactive power:

$$
P_{r}+j Q_{r}=\left(v_{r d}+j v_{r q}\right)\left(i_{r d}+j i_{r q}\right)^{*}
$$

Given that,

$$
v_{s q}=0, \quad i_{s d} \approx-\frac{L_{m}}{L_{s}} i_{r d}, \text { and } \lambda_{s q}=L_{m} i_{r q}+L_{s} i_{s q} \approx-\frac{v_{s d}}{\omega_{d}}
$$

So,

$$
\begin{aligned}
& P_{s}=v_{s d} i_{s d} \approx-\frac{L_{m}}{L_{s}} v_{s d} i_{r d} \\
& Q_{s}=-v_{s d} i_{s q} \approx v_{s d}\left(\frac{v_{s d}}{\omega_{d} L_{s}}+\frac{L_{m}}{L_{s}}\right) i_{r q} \\
& T_{e m}=\frac{p}{2} L_{m}\left(i_{s q} i_{r d}-i_{s d} i_{r q}\right)
\end{aligned}
$$

\subsection{Mathematical model of wind turbine}

The wind turbine mathematically is represented similar to the induction machine:

$$
\frac{d \omega_{\text {mech }}}{d t}=\frac{T_{\text {turb }}-T_{\text {em }, \text { gen }}}{J_{t u r b}}
$$

where $\omega_{\text {mech }}$ here is the mechanically rotational speed of the wind turbine, $T_{\text {turb }}$ is the output torque of the wind turbine, $T_{e m, g e n}$ is the electromagnetic torque of the generator combined with the wind turbine and $J_{\text {turb }}$ is the moment of inertia of the system composed of the wind turbine and the combined generator. The output power is associated with $T_{t u r b}$, as shown below:

$$
P_{\text {out }}=P_{\text {turb }}=T_{\text {turb }} \omega_{\text {mech }}
$$

The power could be extracted by a rotor of area, $\mathrm{A}\left(\mathrm{m}^{2}\right)$, from the wind flux depends mainly on the air density, $\rho\left(\mathrm{kg} / \mathrm{m}^{3}\right)$, the wind speed, $\mathrm{v}(\mathrm{m} / \mathrm{s})$, and rotor aerodynamic efficiency, $\mathrm{C}_{\mathrm{p}}(\mathrm{pu})$, which is known as power coefficient and quantifies the power rate that the rotor extracts, $P_{\text {rotor }}(\mathrm{W})$ :

$$
P_{\text {turb }}=C_{p} P_{\text {wind }}=C_{p} \frac{1}{2} \rho A v_{\text {wind }}^{3}
$$

$C_{p}$ is the aerodynamic efficiency or wind power coefficient.

The wind turbine output power in (19) is represented in Figure 1, where The blue bubbles shows that this power is probably determined based on random wind seed values. It is found the aerodynamic efficiency depends on the tip speed ration $\lambda$ and the blades pitch angle $\beta$, so the output power is rewritten as in (20). 


$$
P_{\text {turb }}=\frac{0.5 \rho \pi R^{2} C_{p}(\lambda, \beta) v_{\text {wind }}^{3}}{\omega}
$$

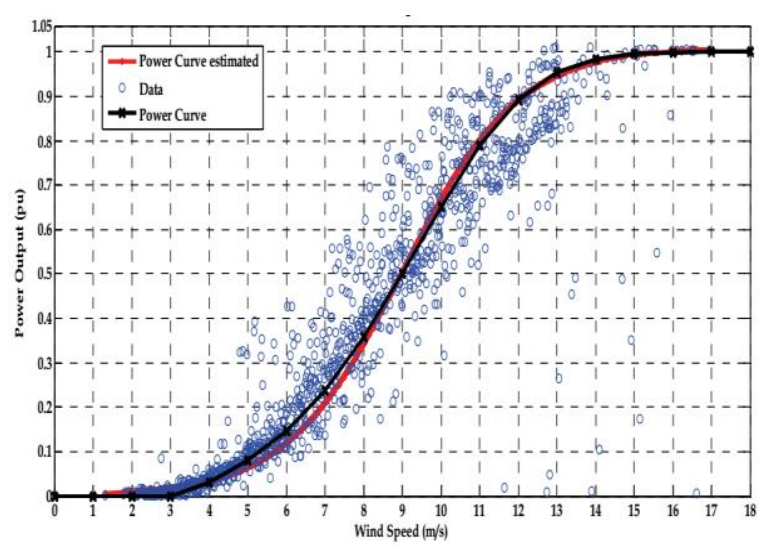

Figure 1. Black curve, Power curve, Red curve, power estimated from the data

In (21) defines the relation between the aerodynamic efficiency and the blades pitch angle:

$$
C_{p}=0.22\left(\frac{116}{\lambda_{i}}-0.4 \beta-5\right) \exp \left(-12.5 / \lambda_{i}\right)
$$

This equation is represented in Figure 2, where power coefficient curves in function of the tip speed ratio and parameterized at different pitch angle values is shown.

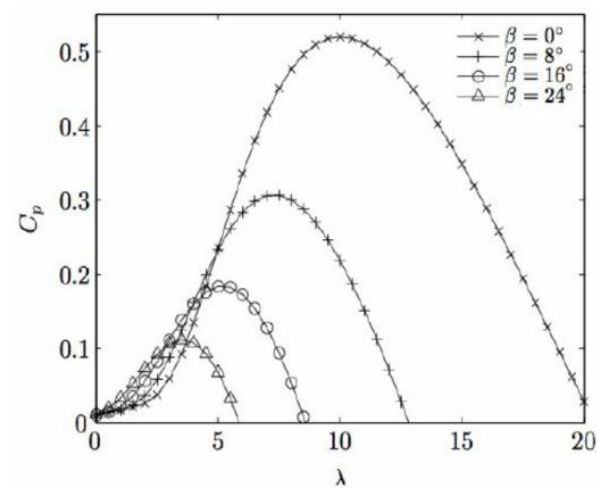

Figure 2. Power coefficient characteristic plotted in function of the tip speed ratio (lambda) and parameterized with the pitch angle (beta)

\section{CONTROLLER DESIGN FOR DFIG-WIND TURBINE}

As mentioned in the previous section, the DFIG model mainly contains three control loops, from the viewpoint of control, which are shown in Figure 3. In the wind turbine control loop, or in other words it is termed as a pitch control loop, the electromechanical torque is controlled in order to supply the maximum allowable power to the grid and to avoid any probable failure for the wind turbine. This loop is described in Figure 4.

The control for the mechanical system of blades of the wind turbine has been executed according to Figure 5. The estimated problems, without applying the control for this loop, are the failure in the mechanical system of the wind turbine and the high hunting of the output power. The rotor-side control loop (RSCL) is the second loop in the DFIG system, as in Figure 6. As shown in this loop, the rotor speed and the rotor excitation should be controlled to be able to apply electromagnetic torque and the rotor excitation current decoupling. For example, the rotor speed is increased if the grid has a voltage dip. Therefore, there is integration between pitch and the rotor controllers. 


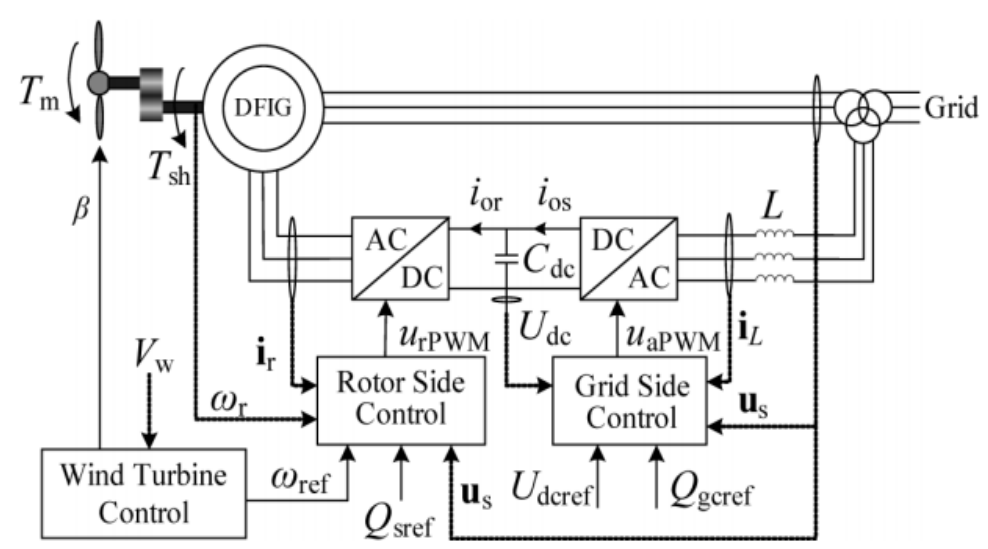

Figure 3. Schematic diagram of the DFIG wind turbine system

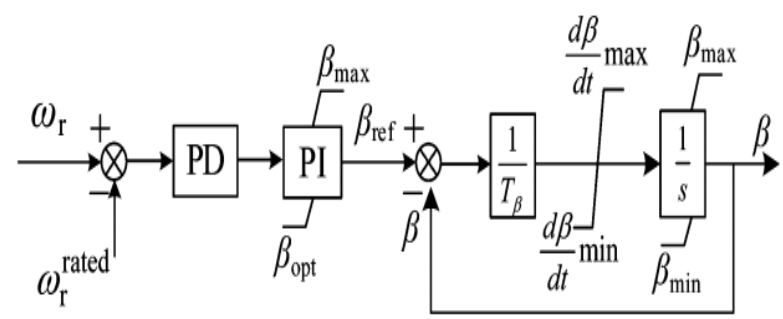

Figure 4. Schematic diagram of the pitch control

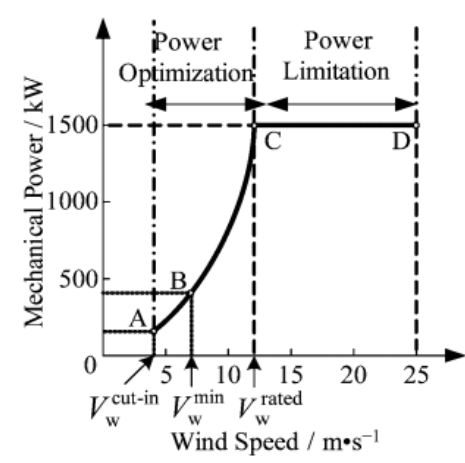

(a)

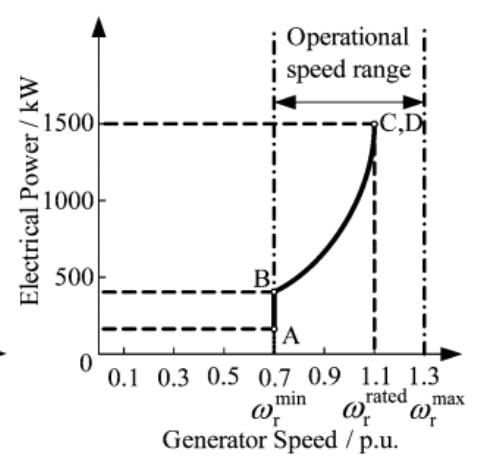

(b)

Figure 5. DFIG WT design static curves, (a) mechanical power- wind speed, (b) electrical power- generator speed

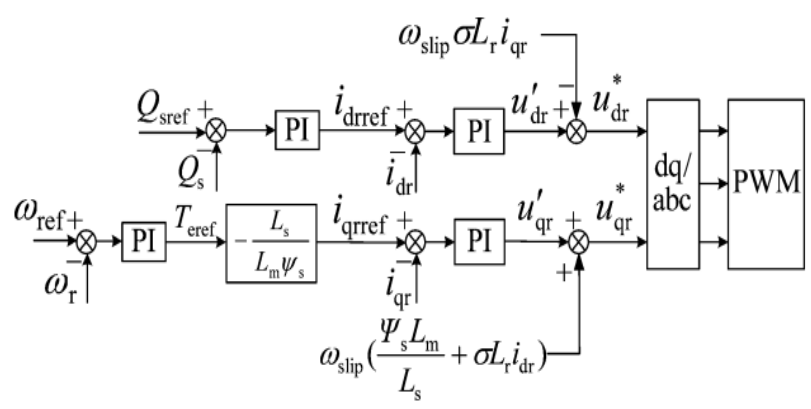

Figuer 6. Rotor-side converter control scheme during normal operation 
The last control loop in the DFIG is grid-side control loop (GSCL). For this control scheme, in order to smoothen the fluctuations of the DC-link voltage, a compensation item is added during the fault, reflecting the variation of the DC-link current of the rotor side converter. Figure 7 shows GSCL control scheme during normal operation, where Udcref and iqlref are the voltage vector of the converter and the current vector of the inductor, respectively. The independent control of active and reactive power flowing between the grid and the GSCL could be obtained by operating the converter control in the grid-voltage oriented reference frame, which is a synchronously rotating reference frame, with its-axis oriented along the grid-voltage vector position [11]. Similarly, the regulation in the DC-link voltage (outer) control loop and the grid side inductor current (inner) control loops are done using typical PI controllers.

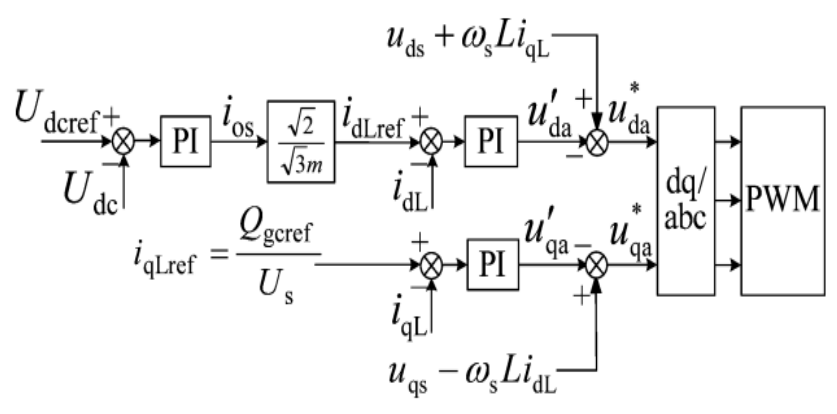

Figure 7. Grid-side converter control scheme during normal operation

The error function of each PI controller is optimized using the IAE, ISE, ITAE, and ITSE.

$$
\begin{aligned}
& I A E=\int_{0}^{\infty}|e(t)| d t \\
& I S E=\int_{0}^{\infty}(e(t))^{2} d t \\
& \text { ITAE }=\int_{0}^{\infty} t \cdot|e(t)| d t \\
& \text { ITSE }=\int_{0}^{\infty} t \cdot(e(t))^{2} d t
\end{aligned}
$$

Finally, the objective function (O.F) of each controller is combined as in (26).

$$
\begin{aligned}
& O \cdot F=\min (e(t)) \\
& O \cdot F=w_{1} \cdot I A E+w_{2} \cdot I S E+w_{3} \cdot I T A E+w_{4} \cdot I T S E
\end{aligned}
$$

Where $w_{i}$ is the weight factor, and the following conditions should be satisfied:

$$
\begin{aligned}
& K_{p_{h}}^{\min }<K_{p_{h}}<K_{p_{h}}^{\max } \\
& K_{i_{h}}{ }^{\min }<K_{i_{h}}<K_{i_{h}}^{\max } \\
& w_{1}+w_{2}+w_{3}+w_{4}=1
\end{aligned}
$$

Here, the symbol $p$ is for the proportional controller, $i$ is for the integral controller, and $h$ denotes the control loop name. The following section gives a brief of the applied optimization algorithm (CSA) in order to obtain the controllers gains and minimize the errors values. 


\section{OPTIMIZATION TECHNIQUE}

The idea of CSA resulted from the idea of how cuckoo birds intruding while searching for a nest for their new babies. It was developed by Xin-she Yang and Suash Deb [17]. These birds put their eggs in host nests, which might be discovered by the hosting birds or not. Cuckoo birds also developed their ways in brood-parasitic, as the females have abilities in the mimicry of the colors of a chosen species to be the host. Their eggs would be in similar colors, which would help in not being discovered. A survey on this technique and its applications was presented in [18]. It was very useful in solving optimization problems in power systems, for example, optimal design of a hybrid power generation system [19], power stabilizers [20], power flow optimization problems [21-23], and economic power dispatch [24-26].

CSA optimization technique could be applied to many controllers to find the best gain values to minimize the error, have optimum system response, and maximize the output power. Tunning of the PI controller [27], PID controller [28, 29], and FOPID controller [30] has been introduced in many applications. In this work, CSA would be applied to tune the gains of the PI and FOPID controllers for the proposed DFIG wind energy conversion system. The algorithm settings as the no. of iterations, and the no. of population, and control parameters would be assigned. Each controller is implemented for the three control loops: rotor-side converter, grid-side converter, and the pitch control loop. Each loop represents a variable, which should be controlled. Both PI and FOPID controllers, separately, would be implemented in each loop. The values of the IAE, ISE, ITAE, and ITSE would be computed for each case. Those values would be compared and analysed to identify the better controller in each loop of the introduced system.

\section{RESULTS AND DISCUSSIONS}

CSA was applied for the PI and FOPID controllers. The settings of the algorithm are shown in the following Table 1. The weights of the error O.F were set to be $\mathrm{w}_{1}=\mathrm{w}_{2}=\mathrm{w}_{3}=\mathrm{w}_{4}=0.25$. The error function was minimized in each of the three control loops and their values were determined as shown in Table 2. Beased on the results in both cases, the IAE, ISE, ITAE, and ITSE of both pitch control loop and the rotor-side control loop was significantly less in case of using the PI controller, except for the ISE value of the second control loop. The PI controller first control loop values were 0.314, 0.493, 2.198, and 3.451, respectively, while the second control loop values were 35.66, 44520, 249.6, and 44520, respectively. It could be noticed that the ISE value of the PI controller equled 44520, which was greater than the same error value of the FOPID controller (27180), but the PI controller values might-generally-be considered with less error's values. However, the FOPID controller gave less errors values for the grid-side control loop, which equaled 39.89, 7956, 279, and 55690, respectively. The values in bold indicates the better values-in general- for each control loop.

Table 1. CSA settings

\begin{tabular}{cc}
\hline Variable & Setting value \\
\hline No. of iterations & 1000 \\
No. of population & 50 \\
Control parameters & $\propto=0.7$ \\
& $P a=0.4$ \\
\hline
\end{tabular}

Table 2. Comparison of applying the PI and FOPID controllers

\begin{tabular}{|c|c|c|c|c|c|c|c|c|}
\hline \multirow[t]{2}{*}{ Control loop } & \multicolumn{4}{|c|}{ PI Controller } & \multicolumn{4}{|c|}{ FOPID Controller } \\
\hline & IAE & ISE & ITAE & ITSE & IAE & ISE & ITAE & ITSE \\
\hline Pitch control loop & 0.314 & 0.493 & 2.198 & 3.451 & 3.156 & 49.81 & 22.09 & 348.7 \\
\hline Rotor-side control loop & 35.66 & 44520 & 249.6 & 44520 & 73.73 & 27180 & 516.1 & $1.902 \times 10^{6}$ \\
\hline
\end{tabular}

The electromechanical torque of the DFIG after applying the controller was determined. Figure 8 represents the tourque after the application of the PI controller, while Figure 9 shows the influence of implementing the FOPID controller. The rotor current was controlled in the second loop. Figure 10 gives the results of applying the PI controller, while Figure 11 illustrates the result of implementing the FOPID controller. There was no difference between using the PI or FOPID controllers while minimizing the error function of the control loop that was responsible for the grid side inverter. Keeping the DFIG terminal voltage within the allowable limits was the main duty of that inverter. Therefore, Figure 12 introduces the output voltage of the DFIG unit for both controllers. 
From the comparative analysis of the results, it could be noted that the PI controller had a general better performance than FOPID controller for the pitch and rotor-side control loop, in additional to its simplicity. In contrast, FOPID controller was the best for the grid-side control loop. These results are might be able to introduce that the PI controller could provide better results than the FOPID controller, which was verified in a previous control model [31]. Based on that analysis, a model incorporating a combined PI and FOPID controllers might be suggested to be implemented in applications.

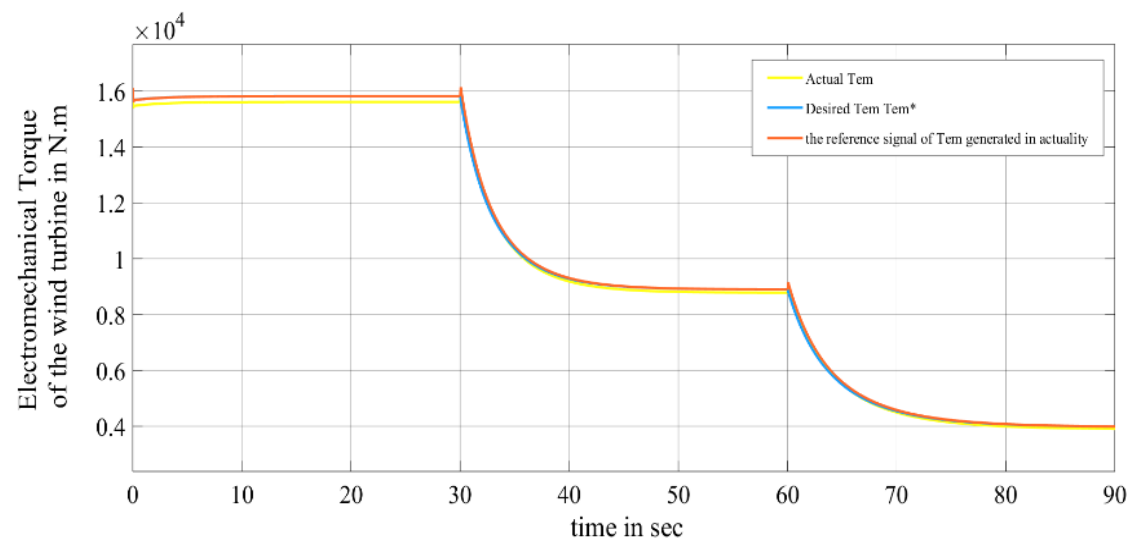

Figure 8. The electromechanical torque of DFIG after applying the PI controller

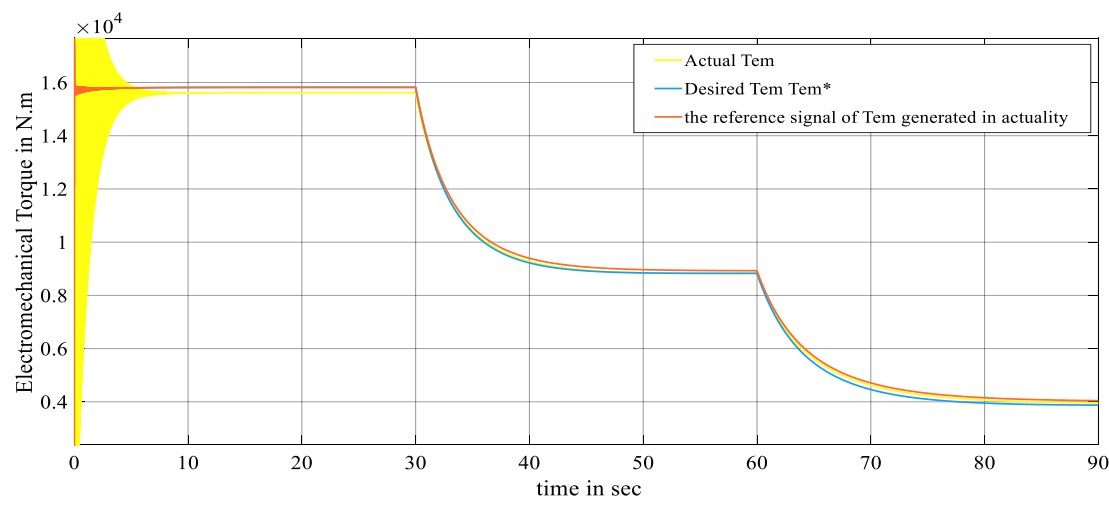

Figure 9. The electromechanical torque of DFIG after applying the FOPID controller

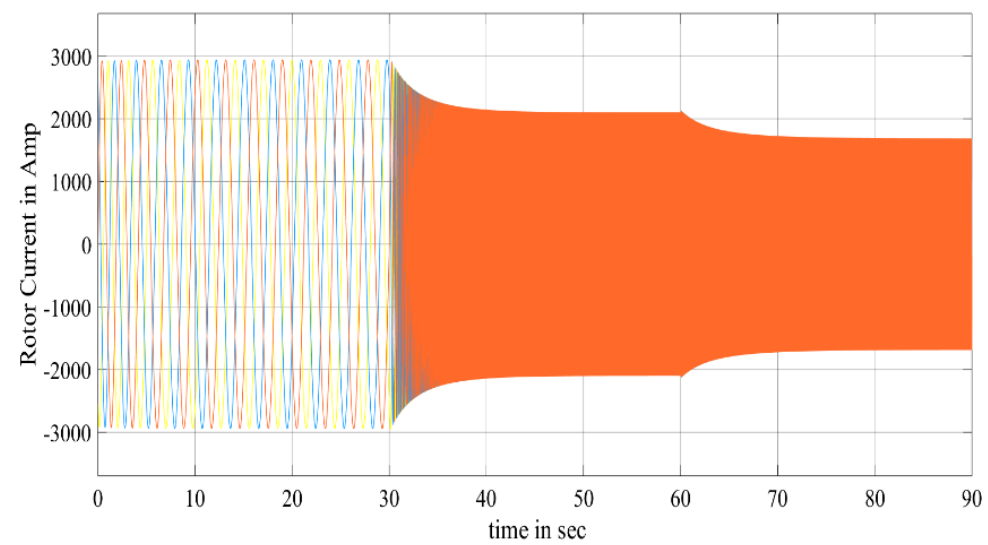

Figure 10. The rotor current of DFIG after applying the PI controller 


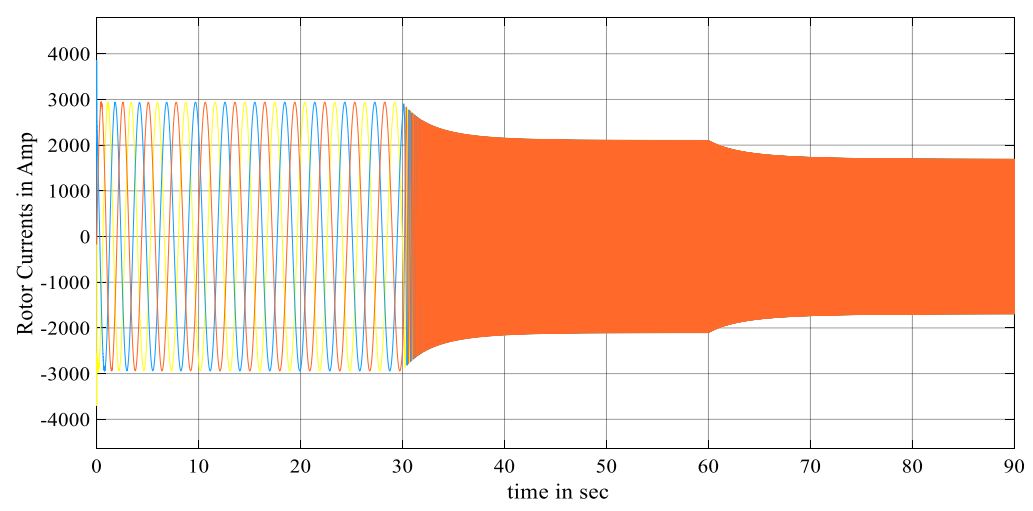

Figure 11. The rotor current of DFIG after applying the FOPID controller

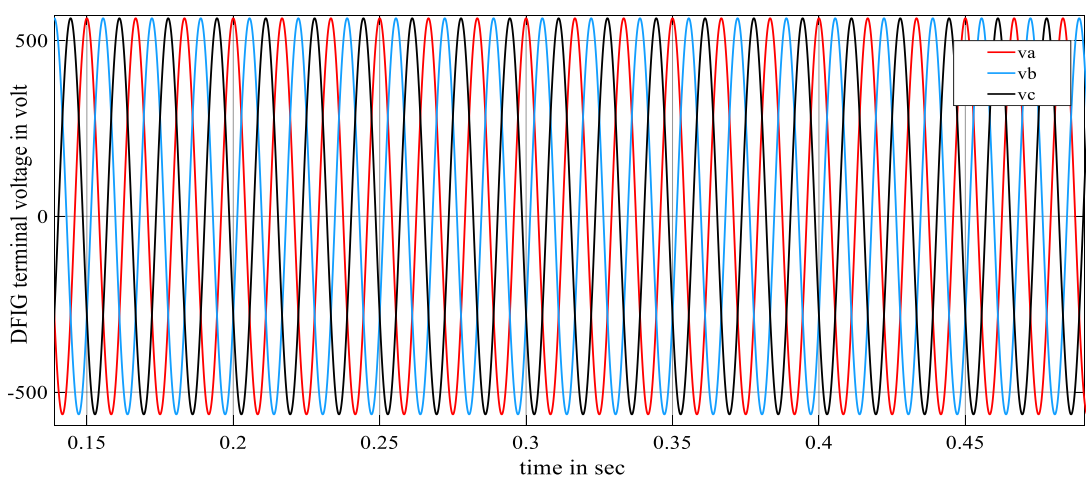

Figure 12. DFIG terminal voltage applying both PI and FOPID controllers

\section{CONCLUSION}

A detailed model for the DFIG has been presented, with three main control loops of this system: pitch control loop, rotor-side control loop, and grid-side control loop. The CSA was applied to tune the gains of each proposed controller. The error function was mininzed considering IAE, ISE, ITAE, and ITSE. It was found that the PI controller gave the simplest and the most effective response for the pitch control loop and the rotor-side control loop while the FOPID controller gave the less errors for the grid-side control loop. Both controllers had the same effect on the terminal voltage as in the grid-side control loop. It might be concluded that a model considering a combination of both controllers could be implemented in future applications.

\section{ACKNOWLEDGEMENTS}

This research was funded by the Deanship of Scientific Research at Princess Nourah bint Abdulrahman University through the Fast-track Research Funding Program.

\section{REFERENCES}

[1] Jason H. Laks, Lucy Y. Pao, and Alan D. Wright, "Control of Wind Turbines: Past, Present, and Future," American Control Conference, pp. 2096-2103, 2009.

[2] F. Wu, X.-P. Zhang, K. Godfrey and P. Ju, "Small signal stability analysis and optimal control of awind turbine with doubly fed induction generator," IET Gener. Transm. Distrib., vol. 1, no. 5, pp. 751-760, 2007.

[3] Junyent-Ferré, A.,et al., "Modeling and control of the doubly fed induction generator wind turbine," Simulation Modelling Practice and Theory, vol. 18, no. 9, pp. 1365-1381, 2010.

[4] O. Barambones, J. Gonzalez de Durana, M. De la Sen, "Robust Speed Control for a Variable Speed Wind Turbine," International Journal of Innovative computing, Information and Control, vol. 8, no. 11, pp. 7627-7640, 2012.

[5] Manale Bouderbala, et al., "Direct and indirect vector control of a doubly fed induction generator based in a wind energy conversion system," International Journal of Electrical and Computer Engineering (IJECE), vol. 9, no. 3, pp. 1531-1540, 2018. 
[6] Dinh Chung Phan, Trung Hieu Trinh, "Maximum Power Extraction Method for Doubly-fed Induction Generator Wind Turbine," International Journal of Electrical and Computer Engineering (IJECE), vol. 8, no. 2, pp. 711-722, 2018.

[7] Lu, Q., Shi, L., and Chen, N., "Study on Optimization Strategy for Voltage and Reactive Power Control of Wind Farm," Physics Procedia, vol. 24, pp. 945-952, 2012.

[8] Boulaam, K., Boukhelifa, A., and Janajreh, I., "A non-linear control of power wind turbine based on Doubly Fed Induction Generator," 1st International Conference and Exhibition on the Applications of Information Technology to Renewable Energy Processes and Systems, pp. 127-131, 2013.

[9] Majdoub, Y., Abbou, A., and Akherraz, M., "Variable speed control of DFIG-wind turbine with wind estimation," International Renewable and Sustainable Energy Conference (IRSEC), 2014.

[10] Salmi Hassan, et al., "PSO-Backstepping controller of a grid connected DFIG based wind turbine," International Journal of Electrical and Computer Engineering (IJECE), vol. 10, no. 1, pp. 856-867, 2020.

[11] Elazzaoui, M., "Modeling and Control of a Wind System Based Doubly Fed Induction Generator: Optimization of the Power Produced," Journal of Electrical and Electronic Systems, vol. 04, no. 1, pp. 1-8, 2015.

[12] O. P. Bharti, R. K. Saket, S. K. Nagar, "Controller design for DFIG driven by variable speed wind turbine using static output feedback technique,” Engineering, Technology and Applied Science Research, vol. 6, no. 4, pp. 1056-1061, 2016.

[13] Wu, Y., K., Yang, W., H., "Different Control Strategies on the Rotor Side Converter in DFIG-based Wind Turbine," Energy Procedia, vol. 100, pp. 551-555, 2016.

[14] Tummala, A. S. L. V., Alluri, H. K. R., and Ramanarao, P. V., "Optimal Control of DFIG Wind Energy System in Multi-machine Power System using Advanced Differential Evolution,” IETE Journal of Research, pp. 1-12, 2018.

[15] S. Albatran, M. I. Alomoush, A. M. Koran, "Gravitational-Search Algorithm for Optimal Controllers Design of Doubly-fed Induction Generator," International Journal of Electrical and Computer Engineering (IJECE), vol. 8, no. 2, pp. 780-792, 2018.

[16] Mohan, Ned. "Advanced electric drives : analysis, control, and modeling using MATLAB/Simulink," John Wiley \& Sons, Inc., 2014.

[17] X. S. Yang andS. Deb, "Cuckoo search via Lévy flights," IEEE Publications World Congress on Nature \& Biologically Inspired Computing (NaBIC 2009), pp. 210-214, 2009.

[18] S. Wahsh, M. Badr, A. Yassin, and M. Algabalawy, "Cuckoo search meta-heuristic algorithm: developments and applications," 5th International Conference on Advanced Control Circuits and Systems (ACCS'017), 2017.

[19] S. F. Mekhamer, et al., "Optimal Multi-Criteria Design of Hybrid Power Generation Systems Using Cuckoo Search and Firefly Algorithms," IEEE, 17th International Middle East Power Systems Conference, 2015.

[20] S. M. Elazim, and E. S. Ali, "Optimal Power System Stabilizers Design Via Cuckoo Search Algorithm," International Journal of Electrical Power \& Energy Systems, vol. 75, pp. 99-107, 2016.

[21] Arul Ponnusamy, and Rengarajan N., "Optimal power flow solution using cuckoo search algorithm," ARPN Journal of Engineering and Applied Sciences, vol. 9, no. 12, pp. 2687- 2691, 2014.

[22] K. P. Nguyen, and G. Fujita, "Self-Learning Cuckoo search algorithm for optimal power flow considering tie-line constraints in large-scale systems," GMSARN International Journal, vol. 12, no. 2, pp.118-126, 2018.

[23] Thang Trung Nguyen, et al., "A Novel Algorithm for Optimal Operation of Hydrothermal Power Systems under Considering the Constraints in Transmission Networks," Energies, pp. 1-21, 2018.

[24] M. Basu, A. Chowdhury, "Cuckoo search algorithm for economic dispatch," Energy, vol. 60, pp. 99-108, 2013.

[25] Benyekhlef LAROUCI, et al., "Cuckoo Search Algorithm for Solving Economic Power Dispatch Problem with Consideration of Facts Devices," U.P.B. Sci. Bull., Series C, vol. 79, no. 1, pp. 43-54, 2017.

[26] J. Zhao, S. Liu, M. Zhou, X. Guo, and L.Qi, "Modified Cuckoo Search Algorithm to Solve Economic Power Dispatch Optimization Problems," IEEE/CAA Journal of Automatica Sinica, vol. 5, no. 4, pp. 794-806, 2018.

[27] Ahmad, M. A. and Ismail, R. R., "A data-driven sigmoid-based PI controller for buck-converter powered DC motor," IEEE Symposium on Computer Applications \& Industrial Electronics, pp. 81-86, 2017.

[28] Zhao, J. and Fu, Z., "Self-tuning of fuzzy neural PID parameter based on chaotic ant colony optimization," AIP Conference Proceedings, AIP Publishing LLC., vol. 2073, no. 1, 2019.

[29] Ghazali, M. R. B., Ahmad, M. A. B. and Raja Ismail, R. M. T. B., "Adaptive safe experimentation dynamics for data-driven neuroendocrine-PID control of MIMO systems," IETE Journal of Research, pp. 1-14, 2019.

[30] Arya, Y., "AGC of restructured multi-area multi-source hydrothermal power systems incorporating energy storage units via optimal fractional-order fuzzy PID controller," Neural Computing and Applications, vol. 31, no. 3, pp. 851-872, 2019.

[31] Ahmed I. Omar, et al., "An improved approach for robust control of dynamic voltage restorer and power quality enhancement using grasshopper optimization algorithm," ISA Transactions, pp. 110-129, 2019. 